\title{
Magic or Not? Sounds vs. Colors in Sexual Selection and Genetic Divergence of Strawberry Frogs
}

\author{
Peter Schausberger* \\ Department of Behavioural Biology, University of Vienna, Vienna, Austria
}

Keywords: sexual selection and mate choice, magic traits, frogs, speciation, acoustic communication, color

\section{A commentary on}

Multiple sexual signals: calls over colors for mate attraction in an aposematic, color-diverse poison frog

by Dreher, C. E., and Pröhl, H. (2014). Front. Ecol. Evol. 2:22. doi: 10.3389/fevo.2014.00022

OPEN ACCESS

Edited by:

Jordi Figuerola,

Estacion Biologica de Doñana -

Consejo Superior de Investigaciones

Cientificas, Spain

Reviewed by:

Pim Edelaar,

Pablo de Olavide University, Spain

James Dale

Massey University, New Zealand

${ }^{*}$ Correspondence:

Peter Schausberger

peter.schausberger@univie.ac.at

Specialty section:

This article was submitted to Behavioral and Evolutionary Ecology,

a section of the journal

Frontiers in Ecology and Evolution

Received: 29 June 2016 Accepted: 08 August 2016 Published: 23 August 2016

Citation:

Schausberger P (2016) Magic or Not? Sounds vs. Colors in Sexual Selection and Genetic Divergence of Strawberry

Frogs. Front. Ecol. Evol. 4:99.

doi: 10.3389/fevo.2016.00099
In many animals, females use multiple signals of the same or different sensory modalities for species recognition and assessing the quality of their mates (Johnstone, 1997). Most interactions between multiple signals can be assigned to two major categories regarding signal integration by the females, that is, multiplicative and sequential (hierarchical) integration (Candolin, 2003). In multiplicative integration, females simultaneously use various signals, which may differ in importance, but all of which are required to make informed decisions. In sequential (hierarchical) integration, females base their decisions on sequential (hierarchical) integration of various signals, starting with the most important ones (Candolin, 2003). Multiple signals used in sexual selection and their interactions are potentially highly important in genetic divergence and speciation but this has been rarely assessed in the field. Sexually relevant traits that both evolve in response to divergent natural selection and contribute to non-random mating, ultimately leading to genetic divergence, are called magic traits (Servedio et al., 2011; Merot et al., 2015).

Dreher and Pröhl (2014) assessed the relative importance of visual and acoustic signals in female choice in six populations of two genetic groups, Northern and Southern, of the Neotropical poisonous strawberry frog Oophaga pumilio in their natural home ranges in Costa Rica and Panama. Geographically separated populations of this species are highly variable in both body color patterns (Daly and Myers, 1967) and acoustic signals (Pröhl et al., 2007). Previous studies revealed color-assortative mate preferences (Maan and Cummings, 2008, 2009) but disregarded the potential relevance of acoustic signals. Dreher and Pröhl (2014) found that acoustic signals, that is, male advertisement calls, were more important in female choice than color patterns. Across populations, females preferred local to non-local advertisement calls, largely unaffected by the simultaneous presentation of local and non-local color morphs of the calling males. In two out of six populations, females going for local calls also displayed a preference for color brightness, which likely correlates with the males' health status and/or toxicity for predators. The findings by Dreher and Pröhl (2014) imply that strawberry frogs use acoustic and visual cues in a sequential (hierarchical) order, with advertisement calls used to attract potential mates from the distance and visual cues gaining importance in close-range mate assessment (Pröhl and Berke, 2001; Pröhl and Ostrowski, 2011). The distance between calling males is probably simply too large, and 
their view often obstructed by habitat features, to allow females visually choosing between males based on coloration.

Most strikingly, Dreher and Pröhl (2014) observed that differences in advertisement calls were associated with genetic divergence, whereas color patterns varied within genetic groups. The strength of acoustic preference for local calls varied among populations, which might indicate different stages of prezygotic behavioral isolation, from loose to almost complete. Presupposing incomplete geographic isolation, allowing at least occasional inter-group and inter-population movement of individuals, pre-zygotic isolation based on calls likely contributes to ongoing divergence between the two genetic groups and among populations within genetic groups. Preference for local calls prevents mating with genetically different, possibly incompatible, conspecific males, and males of genetically closely related species, and might thus decrease the risk of reproductive failure. In contrast to the largely sexually selected acoustic signals, the diversity in color patterns seems primarily the result of genetic drift and/or natural selection and is linked to divergence in toxicity and anti-predator behavior (Pröhl and Ostrowski, 2011).

The study by Dreher and Pröhl (2014) provides a beautiful example of sequential integration of multiple signals in sexual selection and their potential relevance for genetic divergence and speciation. Both acoustic and visual signals are under both natural and sexual selection (Endler, 1983; Heinen-Kay et al., 2015), and thus potentially magic traits, but with reversed primacy. Sounds seem more important in sexual than natural selection. They are inevitable for mate finding and localisation from the distance (which is their primary function) but, as a by-product, advertise the frogs to potential predators. Thus, for acoustic signals, there is a trade-off between natural and sexual selection. Aposematic coloration is important at close range and seems more important in natural than sexual selection. The prime function of the colors is to warn and ward off potential predators. The coloration of males that are better in warding off predators should be more attractive to females, and consequently aposematic coloration becomes relevant in

\section{REFERENCES}

Candolin, U. (2003). The use of multiple cues in mate choice. Biol. Rev. 78, 575-595. doi: 10.1017/s1464793103006158

Daly, J. W., and Myers, C. W. (1967). Toxicity of Panamanian poison frogs (Dendrobates): some biological and chemical aspects. Science 156, 970-973. doi: 10.1126/science.156.3777.970

Dreher, C. E., and Pröhl, H. (2014). Multiple sexual signals: calls over colors for mate attraction in an aposematic, color-diverse poison frog. Front. Ecol. Evol. 2:22. doi: $10.3389 /$ fevo.2014.00022

Endler, J. A. (1983). Natural and sexual selection in poeciliid fishes. Environ. Biol. Fishes 9, 173-190.

Heinen-Kay, J. L., Morris, K. E., Ryan, N. A., Byerley, S. L., Venezia, R. E., Peterson, M. N., et al. (2015). A trade-off between natural and sexual selection underlies diversification of a sexual signal. Behav. Ecol. Sociobiol. 26, 533-542. doi: 10.1093/beheco/ $\operatorname{aru} 228$ sexual selection. Thus, for visual signals, the forces of natural and sexual selection seem aligned. Accordingly, the authors conclude that the preference for bright coloration, observed in two of six populations, could be a consequence of ecological adaptation.

Dreher and Pröhl's (2014) work suggests that color patterns are important within population but play an inferior role in genetic divergence, as compared to acoustic signals. This is probably also a consequence of the spatial scale dependency and hierarchy of acoustic and visual traits in the behavioral sequences of mate finding and choice. The signals' hierarchy mirrors their qualification and importance as magic traits, that is, traits that are involved in both ecological divergence and reproductive isolation, contributing to non-random mating (Servedio et al., 2011; Merrill et al., 2012). In relative comparison, visual signals seem to be of minor importance, due to their secondary role in sexual selection; acoustic signals could qualify as major magic traits if the difference in calls responsible for non-random mating is shaped by differences in ecological constraints, such as predation risk or habitat features. Scrutinizing the ecological factors that co-shape, and correlate with, sexually relevant variation in sounds and colors of strawberry frogs will be a promising, exciting avenue of future research. Elucidating the spatial scale dependency of acoustic and visual signals used in sexual selection and the range of individual movement and dispersal of poison frogs, which is unclear from the study by Dreher and Pröhl (2014), will be key to fully understand past, and predict ongoing, genetic divergence.

\section{AUTHOR CONTRIBUTIONS}

The author confirms being the sole contributor of this work and approved it for publication.

\section{ACKNOWLEDGMENTS}

PS acknowledges funding by the Austrian Science Fund (FWF; P 23504-B17 and P 25876-B25).

Johnstone, R. A. (1997). “The evolution of animal signals," in Behavioural Ecology. An Evolutionary Approach, eds J. R. Krebs and N. B. Davies (Oxford: Blackwell Science), 155-178.

Maan, M. E., and Cummings, M. E. (2008). Female preferences for aposematic signal components in a polymorphic poison frog. Evolution 62, 2334-2345. doi: 10.1111/j.1558-5646.2008.00454.x

Maan, M. E., and Cummings, M. E. (2009). Sexual dimorphism and directional sexual selection on aposematic signals in a poison frog. Proc. Natl. Acad. Sci. U.S.A. 106, 19072-19077. doi: 10.1073/pnas.0903327106

Merot, C., Frerot, B., Leppik, E., and Joron, M. (2015). Beyond magic traits: multimodal mating cues in Heliconius butterflies. Evolution 69, 2891-2904. doi: 10.1111/evo.12789

Merrill, R. M., Wallbank, R. W. R., Bull, V., Salazar, P. C. A., Mallet, J., Stevens, M., et al. (2012). Disruptive ecological selection on a mating cue. Proc. R. Soc. B Biol. Sci. 279, 4907-4913. doi: 10.1098/rspb.2012.1968

Pröhl, H., and Berke, O. (2001). Spatial distributions of male and female strawberry poison frogs and their relation to female 
reproductive resources. Oecologia 129, 534-542. doi: 10.1007/s0044201 00751

Pröhl, H., Hagemann, S., Karsch, J., and Hobel, G. (2007). Geographic variation in male sexual signals in strawberry poison frogs (Dendrobates pumilio). Ethology 113, 825-837. doi: 10.1111/j.1439-0310.2007.01396.x

Pröhl, H., and Ostrowski, T. (2011). Behavioural elements reflect phenotypic colour divergence in a poison frog. Evol. Ecol. 25, 993-1015. doi: 10.1007/s10682-010-9455-5

Servedio, M. R., Van Doorn, G. S., Kopp, M., Frame, A. M., and Nosil, P. (2011). Magic traits in speciation: "magic" but not rare. Trends Ecol. Evol. 26, 389-397. doi: 10.1016/j.tree.2011.04.005
Conflict of Interest Statement: The author declares that the research was conducted in the absence of any commercial or financial relationships that could be construed as a potential conflict of interest.

Copyright (c) 2016 Schausberger. This is an open-access article distributed under the terms of the Creative Commons Attribution License (CC BY). The use, distribution or reproduction in other forums is permitted, provided the original author(s) or licensor are credited and that the original publication in this journal is cited, in accordance with accepted academic practice. No use, distribution or reproduction is permitted which does not comply with these terms. 